\title{
La estela de los huesos: tópicos biopolíticos y necropolíticos en tres textos latinoamericanos recientes
}

Camilo Retana

Retana, C. (2022). La estela de los huesos: tópicos biopolíticos y necropolíticos en tres textos latinoamericanos recientes. Revista de Filología y Lingüística de la Universidad de Costa Rica, 48(1), e48376. doi: https://doi.org/10.15517/rfl.v48i1.48376

\section{(c) $(1) \Theta \Theta$}

Doi: https://doi.org/10.15517/rfl.v48i1.48376

URL: https://revistas.ucr.ac.cr/index.php/filyling/index 
Revista de Filología y Lingüística de la Universidad de Costa Rica

ISSN: 0377-628X

ISSN: 2215-2628

filyling@gmail.com

Universidad de Costa Rica

Costa Rica

\section{La estela de los huesos: tópicos biopolíticos y necropolíticos en tres textos latinoamericanos recientes}

Retana, Camilo

La estela de los huesos: tópicos biopolíticos y necropolíticos en tres textos latinoamericanos recientes

Revista de Filología y Lingüística de la Universidad de Costa Rica, vol. 48, núm. 1, e48376, 2022

Universidad de Costa Rica, Costa Rica

Disponible en: https://www.redalyc.org/articulo.oa?id=33268016010

DOI: https://doi.org/10.15517/rfl.v48i1.48376

\section{(c) $(1) \Theta \Theta$}

Esta obra está bajo una Licencia Creative Commons Atribución-NoComercial-SinDerivar 3.0 Internacional. 


\section{La estela de los huesos: tópicos biopolíticos y necropolíticos en tres textos latinoamericanos recientes}

\section{The Wake of the Bones: Biopolitic and Necropolitic Topics in Three Latin American Recent Texts}

Camilo Retana

Universidad de Costa Rica, San José, Costa Rica

camiloretana@gmail.com

(D) https://orcid.org/0000-0002-6442-7092

\author{
DOI: https://doi.org/10.15517/rfl.v48i1.48376 \\ Redalyc: https://www.redalyc.org/articulo.oa? \\ $\mathrm{id}=33268016010$
}

Recepción: 08 Marzo 2021

Aprobación: 08 Abril 2021

\section{RESUMEN:}

En este artículo me propongo indagar los derroteros seguidos por los cadáveres en tres textos latinoamericanos recientes: "La parte de los crímenes" contenida en 2666 de Roberto Bolaño, Chicas muertas de Selva Almada y Voyager de Nona Fernández. La intuición que guía el texto es que ciertos materiales literarios hacen del cuerpo muerto un sitio de contestación e interrogación de las ontologías fundacionales propias de los actuales órdenes bio y necropolíticos. Dentro de la literatura por examinar, los cadáveres llevan consigo el índice de varias violencias, pero, al mismo tiempo, son portadores de una fuerza crítica y una contumacia que esas violencias no consiguen aplacar.

PALABRAS ClaVE: biopolítica, necropolítica, literatura latinoamericana, cuerpo, memoria.

\section{Abstract:}

In the following article I task myself with inquiring the directions followed by the corpses in three recent Latin American texts: "La parte de los crímenes" contained in 2666 by Roberto Bolaño, Chicas muertas by Selva Almada and Voyager by Nona Fernández. The intuition that leads the text is that certain literary materials make of the dead body a place of response and interrogation of the foundational ontologies that belong to the current bio and necropolitical orders. In the literature examined, the corpses carry the index of several violences but at the same time are carriers of a critical strength and a contumacy that those violences do not manage to soothe.

KEYWORDS: biopolitics, necropolitics, Latin American literature, body, memory.

Nadie domina sobre los muertos, salvo si borra por completo su rastro J. Butler (2020, p. 45).

\section{ACOTACIONES PRELIMINARES: LA ERA BIOPOLÍTICA}

La vida es algo más que su sola condición biológica. Es cierto que el corazón palpita, que la sangre recorre oficiosamente el cuerpo y que, sin el auxilio de los órganos y la laboriosa función de los cerebros, no seríamos nada. Pero también es cierto que ese agregado de células y carne existe dentro de un plexo de sentidos, que el lenguaje configura, organiza y dibuja unos tejidos que se superponen con esos otros tejidos que cubren los huesos, y que ese emplasto de palabra y piel, ese enquiste de significación y mundo es lo que permite que el cuerpo viva.

La biopolítica es el nombre que hemos dado al intento de negar ese exceso irreductible de vida respecto de su constitución estrictamente biológica (Giorgi y Rodríguez, 2009, p. 11). En otras palabras, la biopolítica se refiere a los procedimientos a través de los cuales la vida se intenta limitar a su pretendida constitución natural y el cuerpo a su conformación eminentemente orgánica. La biopolítica constituye un programa cuyo norte es escindir la vida de su forma (Agamben, 2014, p. 21). 
Sin embargo, biopolítica es un vocablo polisémico que designa, en paralelo, varias cosas más, entre ellas, una cierta configuración histórica, una arena de debate crítico y unas ciertas coordenadas de existencia. Los distintos sentidos que orbitan alrededor del concepto conforman una enmarañada red que conviene presentar, en la medida en que es dentro de esa red que se mueve el conjunto de reflexiones de este artículo.

En primera instancia, la biopolítica refiere a una determinada configuración epocal. El teórico francés Michel Foucault, quien en cierto modo inauguró las discusiones sobre biopolítica tal y como las conocemos en la actualidad, ubica la génesis histórica de esta época a finales del siglo XVIII (2010d, p. 655). Pese a que luego Foucault emprende el intento de asir este concepto de diversos modos y a partir de campos socioculturales heterogéneos, con lo cual vacila en su datación, los distintos textos que prepara sobre el tema parecieran coincidir en que, entre finales del siglo XVIII e inicios del XIX, algo fundamental en los discursos sobre el cuerpo, las prácticas sanitarias, los modos de gestión gubernamental y las lógicas con que se ejerce el poder cambia de manera raigal (Foucault, 2009, 2010a, 2010b, 2010c).

Para Foucault, esta inflexión histórica tiene lugar a partir de muchos ámbitos a la vez. La biopolítica es un cambio más o menos simultáneo en campos del saber como la medicina, la criminología, las ciencias políticas, la economía, la estadística y la geografía. En todos esos ámbitos, según Foucault, el siglo XVIII oficia una modificación en los modos en que se imagina la vida y las maneras de protegerla, pero también en las estrategias que se urden para controlarla; en todos esos ámbitos opera una transformación en los mecanismos puestos en marcha para que tal protección y tal control sean posibles. Foucault resume estos cambios al señalar que, "a partir del siglo XVIII, la sociedad, las sociedades occidentales modernas, tomaron en cuenta el hecho biológico fundamental de que el hombre constituye una especie humana” (2009, p. 15). Ese ingreso de lo biológico en la trama de gobierno, esa irrupción de la especie en la gestión de lo social, marcaría para Foucault el inicio de la biopolítica en cuanto período histórico.

Sin embargo, la conceptualización de lo biopolítico en cuanto fenómeno o inflexión histórica va aparejada de una serie de debates teóricos/críticos. Considerada desde esta perspectiva, si se quiere más conceptual que cronológica, la biopolítica se refiere a las discusiones acerca de cómo entender un conjunto de prácticas de poder que tienen en la vida su blanco de acción. En este sentido, la biopolítica ya no menta únicamente unas coordenadas de época, sino también algo que quisiera llamar acá una "epistemología del poder", es decir, un modo de leer o interpretar relaciones de fuerza entre conjuntos de sujetos ${ }^{1}$.

En términos epistemológicos, la biopolítica se caracteriza por ofrecer explicaciones del poder más allá de su dimensión disciplinaria ${ }^{2}$. La biopolítica, si bien comparte con las disciplinas un entramado sociohistórico (ambas forman parte de una suerte de macrodispositivo que Foucault denominó el biopoder) difiere de estas en tanto el control que propone de los cuerpos, así como los resortes de los que dicho control depende, operan de forma un tanto más laxa. Mientras que las explicaciones acerca del poder disciplinario suelen presentar una diagramación del espacio sesudamente diseñada, una atención casi obsesiva a los detalles y una observancia rigurosa de microprescripciones dirigidas al cuerpo, la biopolítica opera a una escala mayor y a partir de cálculos y previsiones que se dirigen a grandes conjuntos poblacionales (Foucault, 2009). Entendidas como aproximaciones conceptuales y como claves comprensivas del poder, la disciplina y la biopolítica difieren, entonces, no solo en su escala (esquemáticamente, aquella opera en lo micro y esta en lo macro), sus mecanismos (la disciplina opera mediante la vigilancia y la sanción, mientras la biopolítica mediante el cálculo y la gestión) y sus lógicas (la disciplina opera constriñendo, mientras la biopolítica dejando hacer), sino, también, en sus alcances (la primera atañe únicamente a individuos a los que hay que corregir, mientras que la segunda a la totalidad de la población) y en los dominios que le resultan propios (el poder disciplinario opera al interior de unas cuantas instituciones, mientras que la biopolítica atraviesa la totalidad de la trama institucional abocada al gobierno de lo viviente).

No obstante estas diferencias conceptuales -acá presentadas de una forma general y por eso mismo un tanto dicotómica-, en la práctica, muchos dispositivos de poder conjugan características de una y otra modalidad. Foucault enfatizó esto a menudo y llegó a hablar de la disciplina y la biopolítica como "dos 
formas principales; no [...] antitéticas [que] constituyen dos polos de desarrollo enlazados por todo un haz intermedio de relaciones” (2005, p. 168). Esa dinámica de tensión, atracción y articulación entre disciplina y biopolítica acaba, por cierto, repercutiendo en las dificultades antes referidas para circunscribir epocalmente esta última, pues dependiendo de cuánto se remarque, ya sea su cercanía o su diferencia con respecto a las modalidades disciplinarias, así la génesis y el epicentro histórico de lo biopolítico variará.

En todo caso, antes que volver sobre el debate historiográfico, me interesa más bien remarcar el hecho de que la biopolítica no refiere únicamente a la irrupción fechable de un cierto estado de cosas, sino también a un criterio de acceso en el análisis del poder. En este segundo sentido, la biopolítica se convierte en una forma de mirar, leer y explicar dinámicas sociales cuyo énfasis está puesto sobre el modo en que la vida biológica se recorta, define, distingue y administra ${ }^{3}$. Así las cosas, la biopolítica, al lado, paralelamente o en sincronía con la delimitación de una forma de poder históricamente localizada, hace referencia también a un modo de pensar, leer y descifrar mecanismos de poder que escapan a esa delimitación histórica. En tanto “epistemología del poder", cabe entonces pensar la biopolítica como una óptica crítica que pone su acento en las fuerzas que pugnan por determinar lo que una vida debe ser. Si la biopolítica en tanto acontecimiento histórico se definía por un interés social creciente y datable por la vida de la especie qua realidad biológica, en su dimensión epistemológica esta misma categoría tendría que definirse como un modo de examinar y aprehender las prácticas de poder posdisciplinarias y el modo en que estas dirimen las formas de existir. En breve: en tanto epistemología, la biopolítica hace referencia a la posibilidad de leer un amplio abanico de violencias que pasan por la definición y cualificación de la vida.

Por último, y aunada a estas dos dimensiones, una histórica y la otra epistemológica, la biopolítica puede entenderse como un conjunto de rasgos que caracterizan nuestra sociedad. Con ello me refiero a que la era que nos ha tocado habitar presenta una serie de coordenadas en las que una y otra vez lo que está en juego es un tipo de administración de la vida en la que se traslapan, hasta casi volverse indiscernibles, lo biológico con lo político, lo médico con lo jurídico, lo sanitario con las políticas de seguridad nacional. Entendido el actual capitalismo posindustrial con vocación transnacional como un entramado cuyo fin es la producción de la totalidad social, incluidos el sujeto, el cuerpo y la naturaleza (Hardt y Negri, 2006), hoy la mayoría de conflictos que se presentan en el mundo tiene que ver con una pugna alrededor de los medios biopolíticos que posibilitan esa producción. Si pensamos en los problemas que dominan la agenda política del siglo XXI (la inmigración, la salud global, los usos y el diseño de nuevas tecnologías, la distribución desigual de los recursos y el alimento a escala planetaria, los cambios en la manera de entender la sexualidad y el género, la implementación de nuevos mecanismos de vigilancia al aire libre o la explotación voraz de los recursos naturales, por mencionar solo algunos), actualmente la política se configura como una disputa por la gestión y producción de la vida misma. Biopolítica es, por ello, también un modo de nombrar nuestro presente: la signatura de un mundo en el que nos corresponde vivir y, por eso mismo, descifrar.

\section{NeCROPOLÍTICA: LA MUERTE COMO EJE GUBERNAMENTAL}

Pese a los alcances hermenéuticos propios de la noción de biopolítica, en América Latina y otras regiones subalternizadas del mundo como África asistimos a un orden sociocultural para el cual dicha categoría no basta. Mientras que la biopolítica tal y como se formuló originalmente en contextos europeos remite a un control del cuerpo viviente, en países periféricos esa modalidad de control colisiona con el hecho de que la muerte sigue siendo un vector de gubernamentalidad fundamental. De ahí que distintos teóricos y teóricas han reconfigurado algunos de los planteamientos foucaultianos antes mencionados con el objetivo de dar cuenta de los modos en que el poder se despliega actualmente en nuestros contextos.

El crítico nigeriano Achille Mbembe, por ejemplo, señala que pensar el desarrollo de los dispositivos biopolíticos en contextos coloniales y poscoloniales implica preguntar si 
la noción de biopoder [...] da cuenta de la forma en que la política hace hoy del asesinato de su enemigo su objetivo primero y absoluto, con el pretexto de la guerra, de la resistencia o de la lucha contra el terror $(2011$, p. 20).

Para Mbembe no resulta tan claro como para Foucault que los actuales regímenes de poder, al menos en nuestras regiones, estén centrados en una gestión de la vida que desconozca la fuerza del plomo y de la sangre. En las formulaciones foucaultianas, la biopolítica constituía un poder de hacer vivir y dejar morir a los sujetos en el marco de un territorio nacional. Para Mbembe, en cambio, hoy tendríamos que hablar de una gestión de lo viviente articulada con un entramado necrológico en el que prima una fusión total entre guerra y política. Dentro del ordenamiento actual, señala el crítico, impera un poder de matar cuya soberanía ya no reside más en el Estado y el Derecho, sino en la guerra, el pillaje y el terror infligido al enemigo. En razón de ello, el protagonismo de agentes no concentrados en plataformas estatales es cada vez mayor, toda vez que estos pueden matar impunemente sin regirse por la soberanía de la ley (podemos pensar, a manera de ejemplos propios de nuestros países, en las estructuras paramilitares de Colombia, las mafias asociadas al narcotráfico en México, o las redes de corrupción financiera en parte privadas y en parte enquistadas en estructuras estatales a lo largo de casi todo el subcontinente).

$\mathrm{Al}$ contrario que Foucault, quien no toma en cuenta el colonialismo como un eje de gubernamentalidad biopolítico, Mbembe señala que la esclavitud primero, y la ocupación colonial después, establecen modos de territorialización en los que la muerte juega un papel fundamental. Así, el necropoder constituye una dinámica de fragmentación territorial a partir de la cual se gobiernan las poblaciones coloniales. Dicho de otro modo, el racismo se convierte en un criterio valorador de la vida que faculta al poder para la segregación de los cuerpos y su disposición espacial. Dentro de los territorios coloniales, la necropolítica apela a nuevas lógicas de gubernamentalidad y nuevos medios para gestionar las multitudes en las que la relación entre cuerpo y muerte juega un papel fundamental. La destrucción (especialmente de los cuerpos, aunque también de los entornos naturales) se convierte en toda una forma de lidiar con los desafíos de gobierno (Mbembe, 2011, p. 63). La crítica de Mbembe apunta, en breve, a mostrar de qué manera la gestión de la vida en contextos coloniales y poscoloniales depende actualmente de la creación de mundos de muerte -a veces con ramificaciones estatales pero casi siempre con carácter paraestatal- en los que convergen fenómenos como la violencia armada, el autoritarismo y la desregulación de la economía.

$\mathrm{Al}$ igual que para Mbembe, para la antropóloga argentina Rita Segato (2016), la muerte constituye un eje fundamental de análisis si se quieren entender los actuales regímenes de violencia -particularmente la ejercida contra las mujeres- y sus nuevas tácticas de control sobre los cuerpos, los territorios y las fronteras. Según Segato, el recorrido histórico a partir del cual Foucault da con la noción de biopolítica debe completarse con un análisis a propósito del empleo actual de tácticas de violencia, tortura y asesinato. Segato señala que tras las huellas del poder soberano y el poder disciplinario, ciertamente hemos ingresado a una época de control sobre las poblaciones, tal y como lo apunta Foucault, pero añade que la característica principal de ese control "es su carácter extensible y fluido en forma de red y ya no su fijación en una jurisdicción administrada por un Estado" (Segato, 2016, p. 66). Dentro de esa disposición reticular y móvil del poder, la gestión biopolítica de los cuerpos vivientes ya no depende únicamente de los límites territoriales fijados en los mapas:

El anclaje anterior de las poblaciones gobernadas dentro de un territorio fijo y nacionalmente delimitado va siendo transformado porque el foco del control se viene dislocando progresivamente hacia un rebaño humano móvil que corta a través de las fronteras nacionales. Por el efecto del paradigma del biopoder, la red de los cuerpos pasa a ser el territorio, y la territorialidad pasa a ser una territorialidad de rebaño en expansión (Segato, 2016, pp. 66-67).

Este tránsito desde paradigmas biopolíticos que, como los descritos por Foucault, dependían de la circunscripción de los rebaños poblaciones dentro de un territorio, hacia unos dispositivos actuales que operan sobre un "rebaño en expansión", tornan el cuerpo una instancia fundamental de marcación. Para Foucault, claro está, no hay poder que no tenga en el cuerpo una superficie de inscripción. No obstante, según este autor la violencia espectacularizante ejercida sobre el cuerpo a la manera de un gesto ostentoso del 
soberano entra en crisis una vez que irrumpen las disciplinas. Segato, en cambio, considera que en Juárez pero podríamos hacer extensivo su análisis a otros lares de Latinoamérica- asistimos a una reemergencia de ese poder soberano a manos de las organizaciones mafiosas.

En sus conocidos análisis a propósito de los asesinatos masivos de mujeres en la frontera entre México y Estados Unidos (Segato, 2016, pp. 33-56), Segato indica que la muerte, la violación y la tortura se han tornado formas a través de las cuales cofradías de hombres mafiosos -nuevos agentes del poder soberano-, expropian a las mujeres de sus espacios/cuerpos para reclamar sobre ellos soberanía física y moral. Para Segato, en esos cruentos asesinatos se juega una violencia expresiva antes que instrumental (2016, p. 39), que hace de los cuerpos el locus de mensajes enviados entre los pares de esas cofradías de hombres mafiosos. La paradoja es que, atendiendo a los postulados de Foucault, la biopolítica no debería ser una política de muerte, pues depende de la existencia de una vida a la cual gestionar - paradoja que, dicho sea de paso, se encuentra en el centro de algunos textos foucaultianos, como El nacimiento de la biopolítica-. No obstante, para Segato, en el caso de los asesinatos en Juárez asistimos a una incorporación de la muerte soberana dentro de una lógica del bios: la vida se encuentra, paradójicamente, administrada bajo la sombra de la muerte.

Como lo señala la autora, "una guerra que resulte en exterminio no constituye victoria, porque solamente el poder de colonización permite la exhibición del poder de muerte ante los destinados a permanecer vivos” (Segato, 2016, p. 38). El cuerpo muerto reporta entonces una utilidad en tanto se torna un terrible lienzo que faculta al envío de mensajes actualizadores de los pactos entre las cofradías de hombres que operan al margen de la ley. En este sentido, poder soberano, poder disciplinario y biopolítica convergen en Juárez en un solo anudamiento en el cual el cuerpo es el nuevo territorio y el cadáver, el sitio de inscripción de la fratría mafiosa y su "pedagogía de la crueldad" (Segato, 2016, p. 179).

En sus reflexiones acerca de las nuevas formas de violencia desplegadas en la frontera entre Tijuana y San Diego, también Sayak Valencia se enfoca en el papel cada vez más preponderante que la muerte juega dentro de las nuevas formas de gubernamentalidad biopolítica. Para Valencia, al igual que para los autores anteriores, el uso predatorio y destructivo del cuerpo despliega una suerte de culto a la muerte. Esta teatralización de la violencia, fundamentalmente ligada al narcotráfico y ejercida principalmente en contra de las mujeres, genera nuevos pactos de gubernamentalidad glorificadores de una cultura criminal que mercantiliza el cuerpo. $\mathrm{Si}$ la biopolítica, tal y como lo señalaba Foucault, remite a un gobierno de la vida en relación con los bienes contenidos dentro de un territorio, según Valencia, las dinámicas de violencia gore convierten el cuerpo en uno más de esos bienes. "Capitalismo gore" designa, por ende, toda una nueva fase del capital en la que el cuerpo y su devastación se tornan una nueva mercancía, y las vísceras y el derramamiento de sangre una fuente de espectáculo y comercio que emula la estética de las películas serie b.

Siguiendo a Mbembe, Valencia señala además que la gestión del cuerpo qua mercancía se ejerce al margen de la estructura estatal. De nuevo la raza emerge acá como un elemento de segmentación poblacional a partir del cual la biopolítica y la necropolítica se despliegan diferencialmente como mecanismos de clasificación de los cuerpos. En este sentido, para Valencia los trazados fronterizos continúan teniendo una vigencia fundamental, toda vez que operan como límites no solo geográficos sino también étnicos que disponen de uno y otro lado mecanismos distintos: en un caso biopolíticos (Estados Unidos) y en el otro necropolíticos (México). De este modo, mientras del lado norte de la frontera los cuerpos se tornan objeto de consumo a través de políticas del cuidado, servicios de salud y promoción de la belleza, del lado sur la mercantilización de los cuerpos toma lugar a partir de lo que la autora denomina "necroempoderamiento", es decir, a través de procesos de apropiación política de los cuerpos más vulnerables mediante el uso de la violencia. Dicho de otro modo, toda vez que las bio/necro/políticas fronterizas se despliegan en Tijuana y San Diego de un modo desigual, dependiendo del lado de la frontera en que se esté, los mercados de la violencia aparecen como alternativa de "pseudoempoderamiento" para los mexicanos empobrecidos. De ahí que la frontera se torne una zona de "bioconsumo" - con su propio "biomercado" - en la que el cuerpo dañado es objeto de transacción por parte de las mafias (Valencia, 2010, pp. 150-154). En este mercado de cuerpos ya no solo la 
vida, sino también la muerte, producen plusvalía. Así, la muerte se ha convertido en un elemento de gobierno toda vez que ha sabido devenir mercado a instancias de fenómenos tan variopintos como los videojuegos, el tráfico de órganos o el sicariato. Dicho en breve, los análisis de Sayak Valencia permiten entender cómo la estetización y profesionalización de la muerte se convierten en formas de administrar las poblaciones que habitan el lado sur de la frontera, al tiempo que habilitan a formas de "necroempoderamiento" y a la creación de nichos de mercado y flujos de capital con la complicidad de un Estado que cada vez es menos el epicentro desde el cual imantan los dispositivos de gubernamentalidad.

Como se puede apreciar, la biopolítica se ha tornado, según la teoría crítica reciente, cada vez más un régimen de muerte que depende, para su adecuado funcionamiento, del exterminio de cierta clase de cuerpos inferiorizados (especialmente los cuerpos racializados y generizados). Este tránsito de lo biopolítico a lo necropolítico lleva consigo, no obstante, algo más que la reinserción de la muerte como vector de gubernamentalidad: en juego se encuentra toda una modificación de las estrategias de espacialización del poder, un cambio respecto de la centralidad de actores al margen de la ley, una instrumentalización de los cuerpos que les devuelve su antiguo estatus de superficie de inscripción del poder soberano y la apertura de una serie de nuevos mercados (alrededor de la guerra, la trata, el narco, etc.) a costa de esos mismos cuerpos.

Frente a este desolador panorama, distintos materiales literarios de los últimos años han venido produciendo narrativas alternativas a propósito del cuerpo y su inserción en el actual mundo biopolítico (Giorgi, 2014). No obstante, si el cuerpo vivo presenta unas capacidades de insurrección biopolítica manifiestas habida cuenta de sus posibilidades latentes de contravenir las normas, acá me interesa discutir más bien la potencialidad de los cadáveres en términos de una crítica necropolítica. A saber: a través de los materiales literarios elegidos, pretendo ir tras la estela de los huesos para así exhumar sus posibilidades críticas.

\section{CONTAR LOS CUERPOS: 2666}

Achille Mbembe caracteriza la necropolítica como una modalidad de poder que tiene "el hueso por objetivo" (2011, p. 65). La violencia del necropoder se dirige inicialmente al cuerpo, pero continúa en la indolencia que se le dirige al cadáver una vez que la vida ha sido liquidada. En los regímenes necropolíticos, los cadáveres no deben ser objeto de rito ni recuerdo, sino que, una vez utilizados en función de su violencia expresiva, pueden ser desechados hasta el punto de tornarse irreconocibles: trozos de materia yerma incapaces, incluso, de abrir surcos en la memoria.

Atendiendo a la historización realizada por Philipe Ariès, en términos generales, la contemporaneidad tiende, de por sí, a una descolectivización despersonalizadora de la muerte (2011, pp. 682-686). Para Ariès, nuestra época se encuentra marcada por una creciente individualización de la experiencia de la muerte, así como por su progresiva privatización. La necropolítica, puede agregarse, exacerba esta condición al reducir el cadáver a su condición de despojo.

Sobre esta disposición es que escribe el narrador chileno Roberto Bolaño en "La parte de los crímenes", uno de los capítulos-novela incluido en su monumental obra 2666. Como se sabe, la narración transcurre en Santa Teresa, la ciudad ficticia donde se desarrolla una violencia que transparenta su filiación con la Ciudad Juárez de la vida real. El texto se compone de un detallado inventario de cuerpos de mujeres asesinadas cuyos cadáveres son arrojados impunemente en basureros, campos baldíos y descampados a lo largo de la ciudad. Las pormenorizadas descripciones de Bolaño incluyen un registro casi forense -el teórico argentino Gabriel Giorgi (2014, p. 214) habla de una "mirada forénsica" presente en la novela- de las circunstancias en las cuales se encuentra cada uno de los cadáveres ${ }^{4}$. Tomemos una de esas descripciones al azar:

A mediados de febrero, en un callejón del centro de Santa Teresa, unos basureros encontraron a otra mujer muerta. Tenía alrededor de 30 años y vestía una falda negra y una blusa blanca, escotada. Había sido asesinada a cuchilladas, aunque en el rostro y el abdomen se apreciaron las contusiones de numerosos golpes. En el bolso se halló un billete de autobús para Tucson, que salía esa mañana a las nueve y que la mujer ya no iba a tomar. También se encontró un pintalabios, polvos, rímel, 
unos pañuelos de papel, una cajetilla de cigarros a medias y un paquete de condones. No tenía pasaporte, ni agenda ni nada que pudiera identificarla. Tampoco llevaba fuego (Bolaño, 2004, p. 446).

Descripciones como esta se repiten una y otra vez a lo largo de "La parte de los crímenes". El texto elude toda clase de parábolas narrativas y a duras penas puede calificarse como una historia propiamente dicha, en la medida en que prácticamente carece de arcos. Es cierto que unos ciertos personajes pueblan el capítulo-novela y que unos cuantos de ellos experimentan algún conato diegético. Sin embargo, el grueso de la novela es eso: páginas y páginas de descripciones de cadáveres, de ocres callejuelas, de bolsos con pertenencias exiguas que parecieran haber vaticinado futuros abolidos. Bolaño no parece interesado en narrar algo, sino en registrar, con una especie de vocación entomológica, las huellas de una crueldad cuya eficacia radica justamente en su condición de inenarrable. Sí, como lo señala Rita Segato, la impunidad reinante en Juárez se sustenta en la ininteligibilidad de los crímenes, el procedimiento escritural de Bolaño puede pensarse como un modo de restituir a los mismos su inteligibilidad.

Lo interesante es que en el marco de esa tarea sean los propios cadáveres los enunciatarios de sentido. En otras palabras, dado que, como lo indica Segato, los cuerpos despojados constituyen un lienzo sobre el cual la fratría escribe su código, el hecho de que esos mismos cuerpos persistan en reclamar su reinterpretación da cuenta de la imposibilidad de un vaciamiento total de su sentido. Los cadáveres de Bolaño se resisten a tornarse nuda vida: se trata de osamentas en cuya contumacia se encuentran grabadas las huellas de una historia ${ }^{5}$.

De ahí la insistencia de Bolaño en el detalle: es como si de la descripción pormenorizada pendiera la capacidad de memorialización de esos cuerpos de otro modo anonimizados. Como lo señala el teórico argentino Gabriel Giorgi,

Los cadáveres de Bolaño son irreconocibles no solo porque en muchos casos aparecen físicamente desfigurados por la violencia, sino también porque el reconocimiento social, jurídico de esos cuerpos, los mecanismos que certifican y aseguran su pertenencia a una comunidad y a un orden social -y que distribuyen persona de no-persona- están inherentemente quebrados: ese quiebre es lo que estos cadáveres hacen visible (2014, p. 215).

Pero además de tornar visible ese colapso de los sistemas ontológicos de reconocimiento e inteligibilidad, las mujeres muertas de la novela llevan consigo los signos de una vida arrebatada (por ejemplo, ese billete a Tucson desaprovechado para siempre). "La parte de los crímenes" insiste muchas veces en trazar la genealogía de esas existencias usurpadas, en recordar los nombres de las difuntas y en caracterizar sus universos vinculares. Así, la tensión entre inteligibilidad e ininteligibilidad se presenta en la novela como un campo de batalla. Si, como lo indica Segato, es "justamente en [la] ininteligibilidad [...] que los asesinos [de Juárez] se refugian, como en un tenebroso código de guerra, un argot compuesto enteramente de acting outs" (Segato, 2016, p. 34), la apuesta de Bolaño es restituir esa inteligibilidad a partir de unos restos que tachan el código de la violencia expresiva que pretendía hablar a partir de ellos.

Esta crítica a la violencia intrínseca a los sistemas de reconocimiento se articula con una cartografía de las mafias y sus formas de operar. Tal y como en los trabajos de Mbembe, Segato y Valencia, en "La parte de los crímenes" se radiografía el carácter fallido del Estado, en principio la instancia llamada a ejercer el control biopolítico. El secuestro de esas funciones a manos de las mafias es retratada en Bolaño con una sarcasmo zaherido. Como en Juárez, en Santa Teresa las investigaciones policiales, los reporteros periodísticos y los políticos están rodeados de una bruma densa y difícil de disipar. Los intentos de investigar las muertes acaban siempre en callejones sin salida, reveladores de la ciega inercia con que se acepta el señorío de las mafias. Pero el anonimato de esas mafias contrasta con la concretud de los cadáveres. Bolaño opone la impersonalidad de los criminales al retrato determinado de las víctimas, como si lo que le interesara fuera invertir la maquinaria abocada a despersonalizar a las mujeres asesinadas.

Un pasaje de "La parte de los crímenes" resulta revelador en este aspecto. En un acto hasta cierto punto desesperado por comprender el móvil de los crímenes, Sergio González Rodríguez, el personaje homónimo 
del periodista que en la vida real escribió Huesos en el desierto, la crónica en la cual se basó Bolaño para escribir "La parte de los crímenes", visita a Florita Almada, una especie de sacerdotisa que dice tener visiones que incluyen detalles de los crímenes. El periodista entrevista a la adivina intentando atisbar alguna pista sobre los perpetradores de los asesinatos. Florita responde elusiva, con vaguedad. No obstante, interrogada a propósito de detalles de los rostros de los asesinos señala que se trata de rostros cualesquiera:

\begin{abstract}
¿Cómo diría usted que son sus caras, Florita? Pues son caras comunes y corrientes [...]. ¿O sea que usted no diría que son caras de asesinos? No [...]. ¿Están enfermos? No lo sé, depende. ¿Depende de qué? De la manera en que uno los mire. ¿Ellos se consideran a sí mismos personas enfermas? No, de ninguna manera. ¿Se saben sanos entonces? Saber, lo que se dice saber, en este mundo nadie sabe nada a ciencia cierta, hijito. ¿Pero ellos se creen sanos? Digamos que sí, dijo Florita (Bolaño, 2004, p. 714).
\end{abstract}

Rostros como cualquiera: espectros de una ciénaga de crueldad asentados en una fachada de normalidad impersonal. Bolaño opone la impersonalidad normalizada de los criminales a la determinación del cadáver. Mientras que los perpetradores de los crímenes devienen en la escritura de Bolaño hombres cualquiera $-\mathrm{y}$ no seres patológicos como lo querría la prensa sensacionalista- las mujeres asesinadas llevan consigo la marca de una historia bien delimitada.

Los cadáveres son, por último, elementos que trazan su propia cartografía de Santa Teresa. "La parte de los crímenes" dibuja un mapa que diagrama las latitudes trazadas por la violencia. Como lo señala Giorgi,

la serie abierta de cadáveres parece apuntar a una ubicuidad de la violencia, dado que no se la puede localizar en una zona, un barrio, un "afuera" de la vida social. Aquí no hay límites o fronteras entre protección y desamparo, entre amparo y exposición [...]. Los cadáveres iluminan ese paisaje de abandono: aparecen "por todos lados” e indican -como si fuesen sus signos- una territorialidad liminar (Giorgi, 2014, p. 219).

Aquí, de nuevo, "La parte de los crímenes" pareciera evidenciar el carácter fallido del Estado y su relevo por parte de las mafias. Sin embargo, los crímenes van más allá al reterritorializar las cartografías políticas y establecer en los dominios jurídico-administrativos del Estado unos nuevos dominios necropolíticos. Empero, hay que decir que en medio de esa geografía terrible, los cadáveres revelan una voluntad obcecada de significar.

En la repetición hipnótica que acaece en el texto, los cadáveres regurgitan una y otra vez, como un obstinado recordatorio de que existe un exceso de vida inatrapable: "los cadáveres, atravesando (e invalidando) las distinciones entre lo público y lo privado, entre lo doméstico y los espacios colectivos refieren una espacialidad fronteriza, inasignable, un espacio que parece exceder modos de inscripción y significación de los territorios" (Giorgi, 2014, p. 219). Todo ocurre como si en ese gesto doble de contar los cuerpos (es decir, de narrarlos pese a su apariencia de inenarrables, al tiempo que se ensaya el inventario casi numérico de sus daños) se reabrieran las posibilidades imaginarias de una reterritorialización alternativa a la de la necropolítica.

\title{
Las Chicas muertas de Selva Almada
}

En Chicas muertas, el libro de crónica de la argentina Selva Almada, asistimos a un escenario en principio ajeno al de 2666. Se trata de un contexto rural, de asesinatos de provincia cometidos en una periferia normalmente leída, según la sensibilidad marcadamente "urbanocéntrica" de los imaginarios porteños, como sin importancia. El universo rural, presente en la obra de Selva Almada ya desde su estupenda novela $E l$ viento que arrasa, aparece aquí como el escenario de crímenes mínimos, anónimos, casi invisibles (me refiero a los terribles asesinatos de Andrea Danne, María Luisa Quevedo y Sarita Mundín). La cronista emprende la investigación a propósito de esas muertes no solo con el objetivo de devolverles visibilidad y de restituir la posibilidad de su luto colectivo, sino también con el objetivo de trazar paralelismos entre asesinatos aparentemente inconexos. Entiéndase bien: Almada no pretende construir un perfil criminológico de los asesinos, sino hacer emerger la estructura necropolítica que los soporta. 
Sin embargo, ese contexto necropolítico que sirve de telón de fondo a la historia no presenta la apariencia de un escenario mafioso como los que describen Sayak Valencia o Rita Segato: aquí estamos en los años 80 y Argentina regresa de su cruenta dictadura; se habla de una vuelta a la democracia y del saneamiento de un tejido institucional que había sido corroído hasta casi desaparecer. Acá no podemos hablar de un Estado fallido, como el de 2666, sino de una institucionalidad que empieza a recobrar sus fuerzas.

No obstante, las noticias de la democracia llegan al lejano ambiente de provincia apenas como un eco distante. Una cierta violencia política se respira todavía en el ambiente. El cadáver de una de las mujeres asesinadas, María Luisa Quevedo, aparece mientras todos celebran la asunción de Raúl Alfonsín y la vuelta de la democracia. Las mujeres asesinadas, pareciera sugerir la cronista, son en cierta medida el remanente de un orden político que había instalado un estado de excepción. Como lo señala Giorgio Agamben (2014), en el estado de excepción prima un levantamiento del orden jurídico mediante el cual se crean umbrales de desechabilidad política de ciertas vidas; el estado de excepción constituye un dispositivo biopolítico en el que se crean las condiciones para matar. La crónica de Almada transcurre en un escenario posdictatorial en el que, precisamente, todavía es posible acometer el aniquilamiento de ciertas vidas sin que quede de ello un registro simbólico o político en el imaginario colectivo. Es como si una cierta ontología necropolítica conectara entre un régimen y otro, o como si existiera una cierta clase de delay por efecto del cual unas cuantas vidas continúan siendo desechables pese al cambio de un modelo político a otro.

Por eso la crónica de Almada se presenta como una apuesta narrativa que opone al orden necropolítico posdictatorial una opción por la memoria. ¿Qué tipo de discurso puede lograr restituir las vidas de las muertas? ¿Cómo ingresar en las bitácoras del recuerdo social unas voces tan abruptamente silenciadas? En el intento de responder a estas preguntas, la narradora recurre, al igual que el Sergio González de Bolaño, al ámbito de lo sobrenatural. Pero la Señora, la tarotista de la crónica, solo es capaz de ofrecer retazos de las vidas que investiga Almada: fragmentos mínimos que no alcanzan para componer el relato que la literatura sí. La crónica de Almada emprende entonces una historización de las chicas muertas que, si bien no devuelve un retrato unitario de las mismas o una resolución de sus crímenes, sí permite reinscribir sus vidas dentro del orden necropolítico que decretó sus muertes. La crónica constituye, de este modo, un dispositivo propicio para un trabajo como este porque permite rastrear las políticas de la memoria concretas que, en la Argentina de los 80, permitieron borrar las vidas y asesinatos de las tres mujeres de las que se ocupa el escrito, a la vez que reinstalarlas dentro de ese archivo paralelo que compone el lenguaje literario. La política escritural de Almada ensaya así un tipo de textualidad para el cual un registro ficcional como el que emplea Bolaño no basta, en la medida en que el desafío está en explicar por qué esas mujeres concretas, de nombres igualmente concretos, y cuyas muertes fueron objeto de atención mediática por un breve momento, fueron luego sumidas en un olvido no solo periodístico, sino también policial y estatal.

Almada desentraña de este modo un terror necropolítico distinto al de escenarios límite como el de Juárez. Esto es: aún en un orden democrático habitual, se desencadenan feroces fuerzas necropolíticas contra los cuerpos de las mujeres que la institucionalidad es incapaz de refrenar. Aún más, se trata de muertes que de algún modo están contempladas dentro de las peculiares formas de estado de excepción que siguen primando dentro de los regímenes democráticos latinoamericanos. Es así que, de nuevo, estamos frente a una lucha por la legibilidad y la posibilidad de rememorar ciertas vidas:

yo creo que lo que tenemos que conseguir [nos dice a sus lectores y lectoras Almada] es reconstruir cómo el mundo las miraba a ellas. Si logramos saber cómo eran miradas, vamos a saber cuál era la mirada que ellas tenían sobre el mundo ¿entendés? (Almada, 2019, p. 109).

Juego de espejos y miradas, la crónica de Almada tiene lugar en medio de un drama por el reconocimiento. Ocurre que en ese mundo de inteligibilidades suprimidas no tiene importancia el modo en que las chicas muertas percibían las cosas. De ahí que haya que emprender la reconstrucción de esas miradas perdidas. Entonces, una vez más, los huesos constituyen el punto de partida para la restitución de una memoria 
abolida. Como no podemos preguntar nada a esas mujeres, como la Señora no es capaz de ofrecer respuestas consistentes, los cadáveres operan como reservorios de memoria, como el locus de una serie de preguntas y de demandas por la justicia que florecen a través de la escritura. Y lo que la cronista encuentra al ir tras la estela de esos huesos es un orden biopolítico signado por la exclusión y la violencia: trabajos mal pagados, desidia policial, desinterés de las autoridades por resolver los casos; pero también mujeres inscritas en universos familiares y afectivos.

El elemento que anuda las vidas y las muertes de las tres mujeres tiene así un cariz necropolítico amén de biopolítico. Si algo articula los tres casos que Almada indaga es su condición de no resueltos. A saber, la obra de Almada se encarga de algo más que de trazar correspondencias entre Andrea, María Luisa y Sarita: muestra el entramado que hace posibles las correlaciones en la vida de todas ellas, así como las condiciones que bloquean la posibilidad de un luto público alrededor de sus muertes. Sin caer en determinismos, la crónica de Almada desdice toda contingencia en el desenlace de las chicas, así como en el hecho de que sus muertes hayan quedado en el olvido. Tras la lectura de la crónica, uno se convence de que cada una de las tres vidas fue, sociológicamente hablando, una variante de la otra.

Como lo ha señalado Judith Butler, parte de los procedimientos biopolíticos de la actualidad pasan por una calificación de las vidas, pero también por una distribución diferencial del duelo que establece qué muertes merecen ser lloradas y qué muertes no (Butler, 2010, pp. 13-56). Las vidas descritas por Almada entran dentro de estas últimas. Por supuesto que en lo privado se trata de vidas que fueron lamentadas; empero, como en Juárez, el atentado contra las vidas de Andrea, María Luisa y Sarita (y del resto de mujeres asesinadas que el libro menciona) permanece en una zona de indeterminación ontológica que les sustrae concretud. Es en busca de devolverles esa concretud que la autora se propone escribir su historia.

¿Mediante qué tenebrosa maquinaria es que estas muertes permanecen impunes? ¿Qué tipo de negociaciones sociales tienen que tener lugar para que atroces femicidios como estos pasen rápidamente al olvido? La necropolítica designa precisamente el conjunto de mecanismos a través de los cuales se disuelven los vínculos sociales que atan estos terribles acontecimientos: el dispositivo mediante el cual se disimulan sus secretas solidaridades.

Aun así, algo de esas vidas sufridas excede la muerte. Los cadáveres alcanzan para que la literatura formule acuciosas interrogantes que de otro modo quedarían en el aire - ¿dónde estás, Sarita?”, pregunta dolorida la autora (Almada, 2019, p. 176) -. A falta de una narrativa que explique qué ha pasado con las chicas muertas, a falta de pistas suficientes para dilucidar lo que pasó con cada una de ellas, la literatura aparece como una respuesta posible, como el soporte capaz de registrar lo que de otro modo permanecería en el registro de lo ontológicamente inarticulable.

\section{VOYAGER: LOS ESPACIOS DE LA MEMORIA}

Mientras en su empeño por crear una bitácora de la violencia necropolítica los trabajos de Roberto Bolaño y Selva Almada recurren a la novela y la crónica respectivamente, en Voyager, la escritora chilena Nona Fernández prefiere apelar al formato de no ficción. La elección de este género no resulta accidental, pues la obra de Fernández no se contenta con una rememoración en clave narrativa, sino que también apunta a recorrer distintos caminos estilísticos que le permitan crear distintos registros de la violencia. Ello ocurre, quizá, en la medida en que Fernández se ocupa de un tipo de escenario necropolítico en el que nos enfrentamos con un desafío distinto al de Bolaño y Almada, a saber, cómo reinstalar la memoria de un cuerpo ausente.

Voyager tiene como punto de partida las desapariciones durante la dictadura militar de Augusto Pinochet. Se trata, entonces, de trabajar sobre la estela de unos huesos sustraídos. En ausencia de ese acervo que es el cadáver en los textos de Bolaño y Almada, Fernández trabaja con otros materiales. El texto se despliega en varios planos, espacios y tiempos a la vez. En simultáneo, el texto procura dibujar el quebranto en la salud de 
su madre, discutir las políticas de Estado que dieron lugar a las Caravana de la Muerte, referir el impacto de la dictadura en el modelo educativo y pensar las superposiciones entre el recuerdo individual y colectivo, entre el tiempo humano y el tiempo cósmico, entre el cuerpo como soporte humano de la memoria y los astros como soporte de una memoria estelar macrosocial. El libro de Fernández opera, en este sentido, como una suerte de artefacto escritural, a la manera de las propias sondas Voyager evocadas en el título, esos extraños objetos ingenieriles lanzados por la NASA al espacio como máquinas de registro. Si las Voyager se componen de diversos elementos para captar y reproducir imágenes, sonidos y ondas, el texto de Fernández trabaja asimismo con múltiples tecnologías para la producción de memoria: el revisionismo histórico, la crítica ensayística, la reconstrucción periodística de hechos y la incorporación de la literatura como práctica dentro de empeños activistas. Se trata de una literatura que funciona como un artefacto productor de memoria.

Pero volvamos a esos cadáveres ausentes en torno a los cuales orbita Voyager. Al igual que Nostalgia de la luz, el espléndido documental de Patricio Guzmán, el texto de Nona Fernández trabaja con la asombrosa transposición simbólica que tiene lugar en el desierto de Atacama: ese sitio que es a la vez el lugar con las mejores condiciones del mundo para observar las estrellas y el perverso escenario en el que veintiséis chilenos fueron asesinados por la Caravana de la muerte de Calama durante de la dictadura de Augusto Pinochet. Los restos de los fusilados fueron aparentemente desechados y desperdigados allí mismo y los cuerpos jamás fueron restituidos a sus familiares. Se sabe que esta misma estrategia de "desmemorialización" fue empleada por varias dictaduras militares en América Latina, pero lo que destaca en el caso de Atacama es que la Agrupación de Familiares de Ejecutados y Detenidos Desaparecidos Políticos de Calama no ha dejado de buscar los restos de los fusilados como un modo de confrontar esa política del olvido. Madres, padres, hermanas y hermanos, hijos e hijas han emprendido la búsqueda de los huesos de sus seres queridos a lo largo de los años.

Como un modo de ingresar a esa batalla por la memoria que se libra en el desierto de Atacama, Fernández narra los efectos de la epilepsia en la capacidad de recuerdo de su madre. Durante breves convulsiones provocadas por la enfermedad, la madre de la autora se vuelve incapaz de registrar lo que acontece: desconexiones neuronales impiden al cerebro llevar el paso de lo ocurrido, componer las constelaciones del recuerdo. Fernández asiste a una cita neurológica al lado de su madre, y en el monitor puede ver proyectado ese paisaje luminoso formado por las reverberaciones del cerebro. La memoria individual, esa constelación hecha de diminutas neuronas conectadas entre sí, se constituye como un espejo diminuto que refleja el modo en que trabaja la memoria colectiva. Como el recuerdo individual, la historia colectiva conoce de cortes y lagunas, pero también de estrategias para resarcirlas.

¿Pero cómo hacerlo? ¿De qué manera restituir esos retazos de acontecimientos no consignados por la conciencia individual/comunitaria? Examinadas estas preguntas en un contexto de torturas y desapariciones forzosas, las estrategias de olvido desplegadas por la dictadura militar se tornan maniobras de desconexión con alcances necropolíticos. La necropolítica introduce disrupciones en las constelaciones de acontecimientos. El terror soberano infundido por la dictadura pinochetista va más allá de la amenaza de muerte, puesto que despliega políticas de espectacularización de la misma (prefiguradoras, por cierto, de la actual violencia hiperespecializada descrita por Sayak Valencia). No obstante, acá, en lugar de una ostentación de la crueldad, lo que se ostenta es un vacío, la interrupción de las conexiones y los enlaces. En última instancia, es la ausencia del cadáver y el tipo de espacialización del desierto que esta entraña, la que faculta a los carabineros a oscuras formas de "necroempoderamiento"; bajo la sombra de la desaparición es que el soberano infunde terror.

De ahí que la restitución del cuerpo muerto se torne una urgencia tanto para los grupos de activistas como para la autora de Voyager. En el contexto del libro, el cadáver se revela como algo más que el soporte material del luto: se trata también de la superficie de inscripción de un sufrimiento colectivo.

Por eso, la consecución del fragmento corpóreo no basta, como lo revela la historia de Violeta Berríos, la fundadora de la Agrupación de Familiares de Ejecutados y Detenidos Desaparecidos Políticos de Calama 
que, tras dar con la mandíbula de su marido Mario Arguelles arrojada en el desierto, y después de décadas de búsqueda, se niega a aceptarla. Describe Fernández:

Durante veinte años estuvo día tras día saliendo temprano a la pampa a rastrear el desierto con sus manos buscando algún hueso de Mario. Una astilla de su cuerpo, el resto de alguna de sus ropas, algo que le permitiera enterrarlo y despedirse de él (Fernández, 2020, p. 574) ${ }^{6}$.

Páginas después Fernández informa el resultado de esos veinte años de búsqueda: "De Mario encontraron una mandíbula. No la quiero, dijo Violeta. Se lo llevaron entero, que me lo devuelvan entero" (Fernández, 2020, p. 658).

En ausencia de ese cuerpo íntegro, la escritura de Fernández se pregunta por posibles caminos alternativos para sostener la memoria. Uno de esos caminos consiste, mediante un gesto que evoca de vuelta Nostalgia de la luz, el documental de Patricio Guzmán, en reinscribir en los cuerpos celestes la memoria del cuerpo desaparecido. Fernández traza una analogía entre las estrellas y la luz que estas nos emiten desde el pasado, y la capacidad evocadora del cuerpo, aún en su ausencia:

todas aquellas luces lejanas que vemos brillar sobre nuestras cabezas vienen del pasado. Según la distancia de la estrella que la emita, podemos hablar incluso de miles de millones de años atrás. Reflejos de estrellas que pueden haber muerto o desaparecido. La noticia de eso no nos llega aún y lo que vemos es el brillo de una vida que quizá se extinguió sin que lo sepamos. Haces de luz que fijan el pasado ante nuestra mirada, como las instantáneas familiares que guardamos en un álbum fotográfico o las figuras del caleidoscopio de nuestra propia memoria (Fernández, 2020, p. 63).

Como los cuerpos de los muertos, los cuerpos celestes nos iluminan desde el pasado: su estela de luz no depende únicamente de la presencia. Fernández elabora esta idea al trabajar en torno al empeño de un grupo de activistas denominado "La constelación de los caídos". Se trata de una campaña de Amnistía Internacional para bautizar veintiséis estrellas con los nombres de cada una de las veintiséis personas asesinadas por la dictadura en el desierto de Atacama. La escritora es invitada a preparar un texto para Mario Arguelles, el marido difunto de Violeta Berríos. En el texto, Mario, como toda estrella, sigue proyectando su estela de luz pese a la muerte. La escritura, de nuevo, se convierte en el registro de una ausencia paradójicamente presente.

Además de restituir esa memoria de Mario proyectándola en el cielo, la escritora procede trazando conexiones, dibujos en el cielo que emulan los signos de la astrología. La constelación se erige como una tecnología para recordar y poner en relación a los caídos. Las veintiséis estrellas forman signos que nos hablan desde el cielo. Si no hay un modo de dar con la tierra donde están los huesos, al menos en el cielo es posible dibujar un trazado estelar que permita recordar esa ausencia. Voyager presenta así la astrología como un modo alternativo (¿una contradisciplina opuesta a los saberes biopolíticos?) de establecer conexiones, como vía para articular lo que de otro modo serían luces desperdigadas en ese otro desierto que es el cielo. Por eso, a partir de la iniciativa de "La constelación de los caídos", Fernández encuentra nuevas posibilidades para la memoria, tira de los puntos aparentemente discontinuos de una historia que, de otro modo, permanecería fragmentada mediante el necropoder. Si los cuerpos de los desaparecidos han sido troceados y desperdigados a lo largo del desierto, el discurso astrológico surge como una alternativa (nótese de nuevo acá la evocación en todos estos materiales del registro paracientífico) capaz de trazar nuevas constelaciones de la memoria: figuras del recuerdo que aten lo que la muerte ha desatado.

En Voyager, así, los muertos siguen sin aparecer, pero sus huesos alcanzan para componer nuevas constelaciones de recuerdos. Si el necropoder trabaja desdiciendo al cuerpo, troceándolo para discutir su integridad, si la necropolítica despliega su fuerza negando a ciertas vidas su estatuto, la literatura se presenta como un recurso para reinstalar esas vidas en el paisaje estelar de la memoria. 


\section{Epílogo}

Los avatares de las sociedades latinoamericanas parecieran cuestionar el diagnóstico foucaultiano: más que sociedades donde se administra la vida, y donde por lo tanto importa conservarla, las nuestras parecieran ser sociedades de muerte que hacen del asesinato un eje de gubernamentalidad. La necropolítica inscribe en los cuerpos y los territorios el terror, sin importar si para ello debe apelar al género, a la clase o a la filiación política como modos de sustraer a los cuerpos su estatuto de vivientes. Sin embargo, allí donde el necropoder hace de la muerte un negocio y del cadáver un mero desecho, la teoría crítica y la literatura se presentan como alternativas para evidenciar y desdecir esos procedimientos.

En especial los materiales literarios acá estudiados presentan una ontología alternativa del cadáver en la que este imanta una fuerza crítica y una pertinacia simbólicas que superan el poder destructivo de la muerte. Es como si frente al poder sombrío de la necropolítica, nuestros cadáveres insistieran en encender el horizonte con su estela.

\section{BibLIOGRAFÍA}

Agamben, G. (2013). Homo sacer. El poder soberano y la nuda vida. Valencia: Pre-textos.

Agamben, G. (2014). Estado de excepción. Buenos Aires: Adriana Hidalgo.

Almada, S. (2019). Chicas muertas. Barcelona: Random House Mondadori.

Ariès, P. (2011). El hombre ante la muerte. Buenos Aires: Taurus.

Bolaño, R. (2004). 2666. Barcelona: Anagrama.

Butler, J. (2010). Marcos de guerra. Las vidas lloradas. Barcelona: Paidós.

Butler, J. (2020). Sin miedo. Barcelona: Taurus.

Esposito, R. (2011). Bios. Biopolitica y filosofía. Buenos Aires: Amorrortu.

Fernández, N. (2020). Voyager. [Versión Kindle]. Recuperado de https://www.amazon.com/-/es/Nona-Fernandez/ $\mathrm{dp} / 8439736304$

Foucault, M. (2005). La voluntad de saber. Historia de la sexualidad, volumen 1. (Trad. U. Guiñazú). México: Siglo XXI.

Foucault, M. (2009). Seguridad, territorio y población. Buenos Aires: Fondo de Cultura Económica.

Foucault, M. (2010a). Defender la sociedad. Buenos Aires: Fondo de Cultura Económica.

Foucault, M. (2010b). El gobierno de sí y de los otros. Buenos Aires: Fondo de Cultura Económica.

Foucault, M. (2010c). El nacimiento de la biopolitica. Buenos Aires: Fondo de Cultura Económica.

Foucault, M. (2010d). Obras esenciales. Barcelona: Paidós.

Giorgi, G. (2014). Formas comunes. Animalidad, cultura, biopolitica. Buenos Aires: Eterna Cadencia.

Giorgi, G. y Rodríguez, F. (Comps.) (2009). Ensayos sobre biopolitica. Excesos de vida. Buenos Aires: Paidós.

Hardt, M. y Negri, A. (2006). Imperio. Buenos Aires: Paidós.

Mbembe, A. (2011). Necropolítica. Tenerife: Melusina.

Segato, R. (2016). La guerra contra las mujeres. Madrid: Traficantes de sueños.

Valencia, S. (2010). Capitalismo gore. Tenerife: Melusina.

\section{Notas}

1 Por "epistemología del poder" no me refiero a un modo de conocer lo que el poder es en sí mismo (pretensión ajena a la mayoría de teóricos y teóricas biopolíticos, empezando por el propio Foucault), sino a un modo de acercarse a su dimensión práctica y a su comprensión dentro de unas coordenadas específicas. 
Revista de Filología y Lingüística de la Universidad de Costa Rica, 2022, vol. 48, núm. 1, e48376, ...

2 La disciplina, tal y como la conceptualizó Foucault en Vigilar y castigar, se caracteriza, como se sabe, por poner en marcha procesos de normalización del cuerpo que operan dentro de distintas instancias sociales (los ejemplos usualmente mencionados por el autor y quienes se han ocupado de desarrollar sus postulados son instituciones como la escuela, el ejército, la fábrica o el manicomio) a partir de dinámicas de serialización, repetición de gestos y punición de conductas. La disciplina, a la vez, sucedió al poder soberano, caracterizado por la concentración de las riquezas, la tierra y sus productos en manos del rey, quien además es dueño de la vida de los súbditos. A propósito de la reemergencia de formas de poder soberano sobre los cuerpos volveré en el apartado siguiente.

3 Teóricos contemporáneos como el italiano Giorgio Agamben (2013) -quien encuentra visos de mecanismos biopolíticos en contextos tan heterogéneos como el derecho romano o la cultura cristiana-, el crítico Roberto Esposito (2011) - para quien los campos de concentración constituyen la hipérbole del poder biopolítico- o los pensadores Hardt y Negri (2006), -para quienes el capitalismo propio de nuestro presente está plagado de biopolítica por todas partes- se permiten extrapolar los análisis en clave biopolítica a regiones, períodos y campos que habrían resultado en arreglo con el recorrido histórico inicialmente ensayado por Foucault.

4 Formas comunes, de Gabriel Giorgi, constituye desde ya, en mi criterio, una obra de referencia para cualquier discusión sobre las relaciones entre biopolítica y literatura latinoamericana. El presente artículo, de hecho, constituye en varios sentidos un intento de continuar algunas de las conversaciones iniciadas por Giorgi.

5 Para una caracterización de la conocida noción de nuda vida, acuñada por Giorgio Agamben, puede consultarse, entre otras fuentes del autor, Homo sacer. El poder soberano y la nuda vida (2013, pp. 9-23). En el contexto del presente escrito puede pensarse la nuda vida a la manera de un cuerpo al cual se ha sustraído toda capacidad de significación.

6 A falta de paginación en la versión ebook consultada, se referencian las citas de la obra de Fernández por medio de la posición. 